\title{
Efficiency of Airborne Sample Analysis Platform (ASAP) bioaerosol sampler for pathogen detection
}

OPEN ACCESS

Edited by:

Yasuko Tsunetsugu Yokota, National Institute of Infectious

Diseases, Japan

Reviewed by:

Fumitaka Momose,

Kitasato University, Japan

Marta Canuti,

Memorial University of Newfoundland,

Canada

Masahito Hosokawa

Waseda University, Japan

*Correspondence:

Suresh K. Mittal,

Department of Comparative

Pathobiology, College of Veterinary

Medicine, Purdue University,

West Lafayette, IN 47907, USA

mitta@@purdue.edu

tPresent address:

Anurag Sharma

Department of Pediatrics,

Weill Cornell Medical College, New York, NY, USA

Elizabeth Clark,

Department of Biology, University of California at San Diego, La Jolla, CA,

USA

Specialty section:

This article was submitted to

Virology,

a section of the journal

Frontiers in Microbiology

Received: 10 February 2015

Accepted: 08 May 2015

Published: 27 May 2015

Citation:

Sharma A, Clark E, McGlothlin JD

and Mittal SK (2015) Efficiency

of Airborne Sample Analysis Platform

(ASAP) bioaerosol sampler

for pathogen detection.

Front. Microbiol. 6:512.

doi: 10.3389/fmicb.2015.00512

\author{
Anurag Sharma ${ }^{1 \dagger}$, Elizabeth Clark ${ }^{1 \dagger}$, James D. McGlothlin ${ }^{2}$ and Suresh K. Mittal ${ }^{1 *}$ \\ ${ }^{1}$ Department of Comparative Pathobiology, College of Veterinary Medicine, Purdue University, West Lafayette, IN, USA, \\ ${ }^{2}$ School of Health Sciences, College of Health and Human Sciences, Regenstrief Center for Healthcare Engineering, Purdue \\ University, West Lafayette, IN, USA
}

The threat of bioterrorism and pandemics has highlighted the urgency for rapid and reliable bioaerosol detection in different environments. Safeguarding against such threats requires continuous sampling of the ambient air for pathogen detection. In this study we investigated the efficacy of the Airborne Sample Analysis Platform (ASAP) 2800 bioaerosol sampler to collect representative samples of air and identify specific viruses suspended as bioaerosols. To test this concept, we aerosolized an innocuous replication-defective bovine adenovirus serotype 3 (BAdV3) in a controlled laboratory environment. The ASAP efficiently trapped the surrogate virus at $5 \times 10^{3}$ plaque-forming units (p.f.u.) $\left[2 \times 10^{5}\right.$ genome copy equivalent] concentrations or more resulting in the successful detection of the virus using quantitative PCR. These results support the further development of ASAP for bioaerosol pathogen detection.

Keywords: bioterrorism, airborne pathogens, air samples, ambient air sampler, virus detection, pathogen detection, pandemic, bioaerosol

\section{Introduction}

In the current global geopolitical environment, the threat of a terrorist attack on the US and international community has never been greater. A biological threat of great concern to public safety is the use of an aerosolized pathogenic micro-organism that can be spread in the air as happened with the anthrax attack of 2001 (Zink, 2011; Menrath et al., 2014). In addition, an individual infected with a deadly pathogen can transmit the pathogen at a high human density place or event. Some highly contagious and fatal biological agents that are considered as bio-terror agents include Bacillus anthracis, Yersinia pestis, small pox, or Marburg viruses and other emerging pathogens (Pohanka and Kuca, 2010; Menrath et al., 2014).

Besides the intentional release of bioaerosols, natural outbreaks of infectious diseases may occur without warning. Outbreaks including Severe Acute Respiratory Syndrome (SARS) in 2002-2004 (Christian et al., 2004), continuously evolving influenza virus strains (Khanna et al., 2008) and recent infections with Middle East respiratory syndrome coronavirus (MERSCoV; Hartl, 2013) underscore that such a natural threat is a real possibility. Early detection of the pathogen can result in prompt intervention and treatment of exposed individuals as well as confine the secondary spread. Because of the high global mobility of people, the failure to detect an intentional or natural outbreak of a contagious disease could result in its rapid spread with catastrophic consequences. In order to effectively safeguard against such threats, it is critical to continuously monitor the air for the presence of pathogenic 
biological agents, particularly at high risk events or places such as airports, malls, subway stations, cruise ships, aircraft, theaters, stadiums, or schools. Such an approach requires an advanced system that can continuously sample the ambient air for pathogen detection.

Following the acquisition of an air sample, many different approaches including genome detection (Pyankov et al., 2007; Goransson et al., 2012; Usachev and Agranovski, 2012), immune (McBride et al., 2003; Rider et al., 2003; Skottrup et al., 2008), optical (Pan et al., 2003; Sengupta et al., 2007), or other biochemical assays (Hagleitner et al., 2001; Ho, 2002) have been employed for specific detection of a large selection of pathogens including bacteria, fungi, virus, or toxins. Since nucleic acids are the absolute biomarkers, quantitative polymerase chain reaction (qPCR) or quantitative reverse transcriptase-PCR (qRT-PCR) is strongly established as the method of choice for accurate, sensitive and specific identification of a number of pathogens in the same sample (Oppliger et al., 2011).

The Airborne Sample Analysis Platform (ASAP) 2800 (Thermo Scientific, USA) bioaerosol sampler provides an effective means of collecting representative samples of air for subsequent laboratory analysis. At a flow rate of $200 \mathrm{l} / \mathrm{min}$, this sampler pulls in the air which impacts on a piece of polyurethane foam (PUF) inside a cassette called Integrated Bio Aerosol Sampling System (iBASS) cartridge (Figure 1). In this study we investigated the efficiency of the ASAP system to acquire an aerosolized viral pathogen and detect it using a Taqman qPCR. For testing, we aerosolized an innocuous replicationdefective bovine adenovirus serotype 3 (BAdV3) in a controlled laboratory environment. The ASAP system successfully trapped the virus-loaded aerosols which were subsequently detected by qPCR.

\section{Materials and Methods}

\section{Surrogate Virus and Cell Line}

Replication-defective BAdV3 with E1 and E3 deletions (BAd$\triangle \mathrm{E} 1 \mathrm{E} 3)$ was constructed and propagated in fetal bovine retinal cells transformed with adenoviral E1 (FBRT-HE1) as described elsewhere (van Olphen et al., 2002; Sharma et al., 2009). The FBRT-HE1 cells were grown as monolayer cultures in Eagle's Minimum Essential Medium (MEM; Life Technologies, Gaithersburg, MD, USA) and supplemented with $10 \%$ reconstituted bovine serum (Fetal Clone III; Hyclone, Logan, $\mathrm{UT}$ ) and $50 \mu \mathrm{g} / \mathrm{mL}$ gentamycin. The virus purification was done by cesium chloride-density gradient centrifugation as previously described (Graham and Prevec, 1991). The titration of virus was done in FBRT-HE1 cell lines by plaque assay and expressed as plaque forming units (p.f.u.)/mL. The DNA from the purified virus was isolated, and genome copy equivalent of the virus was calculated with the following formula where the ratio of genome copy number to p.f.u was 40 .

Number of virus genome copies $=\frac{\left(\text { DNA amount }(\mathrm{ng}) \times 6.022 \times 10^{23}\right.}{\left(\text { Lenght }(\mathrm{bp}) \times 10^{9} \times 650\right)}$

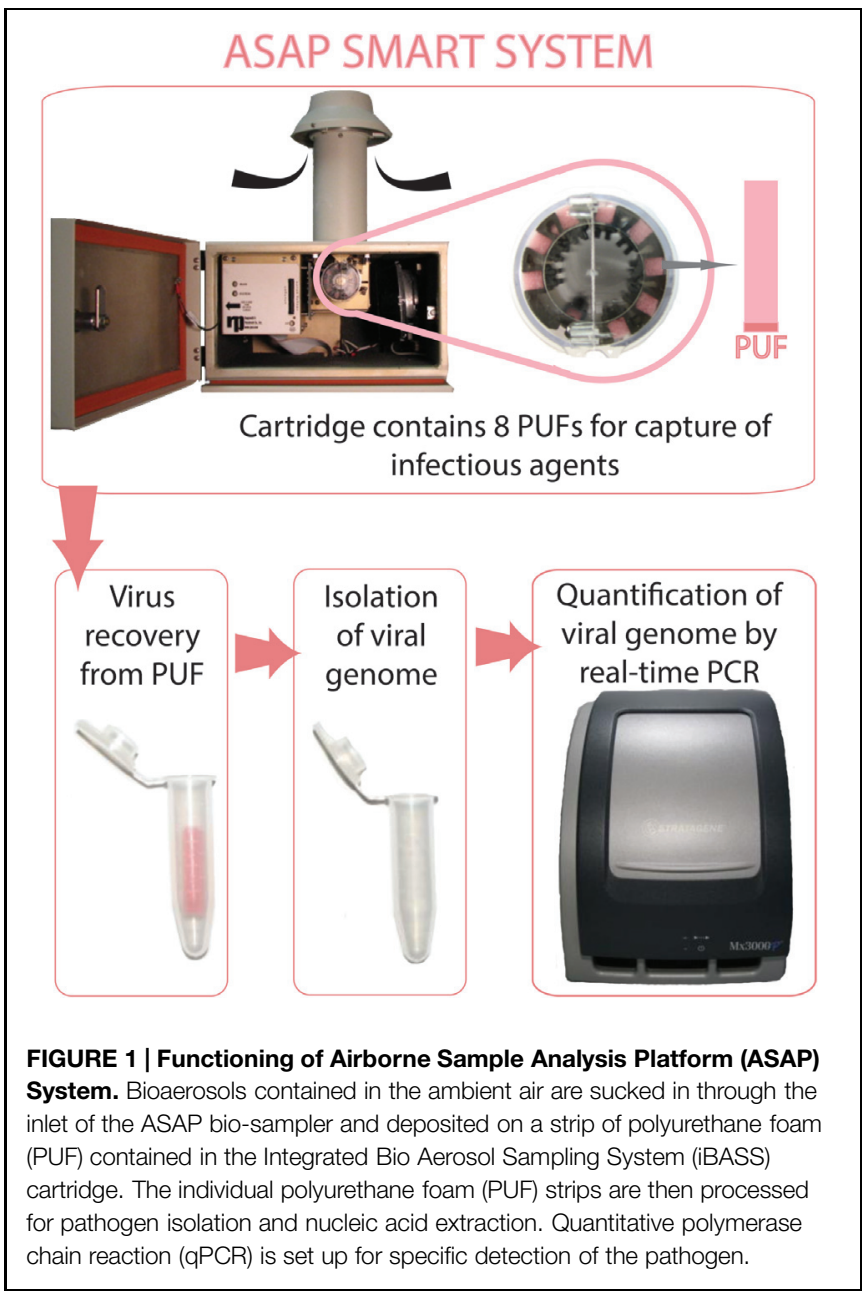

\section{Isolation of Viral DNA}

Purified BAd- $\triangle$ E1E3 particles at various dilutions $\left(0,5 \times 10^{1}\right.$, $5 \times 10^{3}, 5 \times 10^{5}$, or $5 \times 10^{7}$ p.f.u.) in $50 \mu \mathrm{L}$ were spiked in the strips of PUF of the ASAP system. Virus was recovered by adding $500 \mu \mathrm{l}$ PBS to the PUFs and squeezing the liquid out of the PUFs by centrifugation. Un-spiked virus samples served as controls for the determination of virus recovery from the PUFs. DNA was isolated using the DNAzol reagent (Molecular Research Center). The isolated DNA was resuspended in $25 \mu \mathrm{L}$ of distilled water, and the amounts of extracted nucleic acid were quantified by a $\mathrm{qPCR}$ assay using known amounts of purified BAd- $\triangle \mathrm{E} 1 \mathrm{E} 3$ nucleic acid as standards.

The efficiency of virus recovery was calculated as -

Efficiency $=$

Copy number of virus genome recovered from spiked samples

Copy number of virus genome recovered from purified virus $\times 100$

\section{Primers and Taqman Probes}

Specific primers and a Taqman probe targeting the $\mathrm{E} 4$ region of BAdV3 were designed using Primer Express 2.0 software (Life Technologies). The sequence of primers and probes are as follows: 
Forward primer - 5' - GGGCGAGCAATCAGCTCTTA - 3' Reverse primer $-5^{\prime}$ - CTAATCCACTGCCCATGTACACA - $3^{\prime}$ Probe - 5' - AGTCCCTGCCCACTTTTGCCTGG - 3'

The oligonucleotides were synthesized by Applied Biosystems. The probe was labeled with FAM (6-carboxyfluorescein) at the $5^{\prime}$ end and with MGB (minor groove binder) at the $3^{\prime}$ end. The primers and probes were reconstituted in TE buffer, aliquoted, and stored at $-20^{\circ} \mathrm{C}$ until required.

\section{Quantitative PCR}

For absolute quantification of the viral genome, a standard curve was obtained using serial 10-fold dilutions (three copies to $3 \times 10^{7}$ copies in $10 \mu \mathrm{l}$ ) of purified genomic DNA of BAd$\triangle \mathrm{E} 1 \mathrm{E} 3$. The copy number of the viral genome was calculated based on spectrophotometric quantification and the molecular mass of BAd- $\triangle E 1 E 3$ 's genomic DNA. A standard curve was run for each set of assays. For qPCR, $10 \mu \mathrm{L}$ of isolated DNA was used in a $25 \mu \mathrm{L}$ reaction using Taqman PCR core reagents (Applied Biosystems, Foster City, CA, USA). The reaction mixture contained 10x Taqman buffer, $250 \mathrm{nM}$ of forward and reverse primers, and $100 \mathrm{nM}$ of Taqman probe along with other standard kit components. Each reaction was carried out in duplicate. The qPCR was performed using the Mx3000 Thermocycler (Stratagene, Cedar Creek, TX, USA) with the following reaction conditions: $50^{\circ} \mathrm{C}$ for $2 \mathrm{~min}$, followed by polymerase activation $\left(95^{\circ} \mathrm{C}\right.$ for $\left.10 \mathrm{~min}\right), 45$ cycles of denaturation $\left(95^{\circ} \mathrm{C}\right.$ for $\left.15 \mathrm{~s}\right)$ and annealing/extension $\left(60^{\circ} \mathrm{C}\right.$ for $\left.1 \mathrm{~min}\right)$. The threshold cycle (Ct) value for individual reactions was determined, and data was analyzed with MxPro software to obtain the absolute copy number of viral genome.

\section{Evaluation of the Efficiency of Airborne Sample Analysis Platform (ASAP System) in Trapping Aerosolized Virus Particles}

The basic procedure used to test the efficiency of the ASAP System is depicted in Figure 1. The ASAP System was placed in a biosafety cabinet $[72$ inches $(183 \mathrm{~cm}) \times 24$ inches $(61 \mathrm{~cm}) \times 28$ inches $(71 \mathrm{~cm})]$ and various dilutions $\left[0,5 \times 10^{1}, 5 \times 10^{2}\right.$, $5 \times 10^{3}, 5 \times 10^{4}, 5 \times 10^{5}, 5 \times 10^{6}$, or $5 \times 10^{7}$ p.f.u. (i.e., $0,2 \times 10^{3}$, $2 \times 10^{4}, 2 \times 10^{5}, 2 \times 10^{6}, 2 \times 10^{7}, 2 \times 10^{8}$, or $2 \times 10^{9}$ genome copies equivalent)] of BAd- $\triangle \mathrm{E} 1 \mathrm{E} 3$ in $0.5 \mathrm{ml}$ were aerosolized with the help of a vibrating mesh nebulizer system (Micro Air, Omron) which was kept at distances of six inches $(15 \mathrm{~cm})$, one foot $(30 \mathrm{~cm})$, and 4 feet $(122 \mathrm{~cm})$ from the air intake trap of the machine. The machine was allowed to run for an additional 15 min after the completion of the aerosolization of each sample. Each dilution was run in triplicate. One PUF per cartridge was not exposed to the aerosols and was kept as a negative control. After the run, each PUF was collected from the iBASS cartridge. The nucleic acid was extracted from the virus trapped in the PUF using the DNAzol reagent as per the manufacturers' protocol and resuspended in $25 \mu \mathrm{L}$ of distilled water. The amounts of recovered nucleic acid were quantified by qPCR.

In addition, to mimic the conditions in a normal work environment, the same experiment was also conducted in a room [ 9 feet $(274 \mathrm{~cm}) \times 10$ feet $(305 \mathrm{~cm}) \times 10.8$ feet $(329 \mathrm{~cm})]$ with a regular ventilation system. This time the aerosols were created by placing the nebulizer at greater distances $[5$ feet $(152 \mathrm{~cm})$ and 10 feet $(305 \mathrm{~cm})$ ] from the ASAP system. ASAP was allowed to run for an additional $1 \mathrm{~h}$ after completion of the aerosolization of each sample. This was followed by extraction of nucleic acid and quantitation by qPCR. All experiments including aerosolization of virus were conducted as per approved institutional biosafety protocols.

\section{Results}

\section{Selection of a Surrogate Virus}

In order to explore the usefulness of the ASAP system as a rapid detection system for highly pathogenic agents in air samples, we needed a surrogate virus which was safe but could mimic the air sampling procedure that will be required for detecting highly pathogenic infectious agents. We selected a replicationdefective bovine adenovirus (BAd- $\triangle \mathrm{E} 1 \mathrm{E} 3$ ) having deletions in the early region (E) 1 (E1) and E3. The E1 gene products are essential for adenovirus replication; therefore, such E1-deleted viruses can be grown only in cell lines that constitutively express E1. Even wild type BAdV3 is not pathogenic in human or animals. For quantification of BAd- $\triangle \mathrm{E} 1 \mathrm{E} 3$ genomes by $\mathrm{qPCR}$, a standard curve was generated using serial dilutions of known amounts of BAd- $\triangle$ E1E3 genomes as standards (Figure 2A). The detection limit of our qPCR assay was three genomes of BAd- $\triangle \mathrm{E} 1 \mathrm{E} 3$.

\section{Nucleic Acid Recovery from PUFs of ASAP System}

Since the sensitivity of the ASAP system also depends on the efficiency of nucleic acid recovery from the PUFs containing the trapped infectious agent, we spiked various amounts of purified BAd- $\triangle$ E1E3 onto the PUFs and processed them for nucleic acid extraction by DNAzol (Molecular Research Center). The amounts of extracted nucleic acid were quantitated by qPCR, and known amounts of purified BAd- $\triangle \mathrm{E} 1 \mathrm{E} 3$ nucleic acid served as standards. The recovery of nucleic acid by this method was approximately $88 \%$ (Table 1 ).

\section{Evaluation of the Efficiency of ASAP System in Trapping Aerosolized Virus Particles}

Before conducting experiments, we determined the efficiency of the ASAP system in trapping aerosolized virus particles in addition to the likelihood of cross-contamination from one PUF to another PUF in the iBASS cartridge. The ASAP System was placed in a biosafety cabinet and various amounts $(0$, $2 \times 10^{3}, 2 \times 10^{4}, 2 \times 10^{5}, 2 \times 10^{6}, 2 \times 10^{7}, 2 \times 10^{8}$, or $2 \times 10^{9}$ genome copies equivalent per $0.5 \mathrm{ml}$ ) of BAd$\triangle E 1 E 3$ were aerosolized with the help of a nebulizer kept at distances of six inches $(15 \mathrm{~cm}), 1$ foot $(30 \mathrm{~cm})$, and 4 feet $(122 \mathrm{~cm})$ from the air intake trap. Each sample was run in triplicate. After the run, each PUF was collected from the cartridge, and the nucleic acid was extracted from the virus trapped in the PUF using the DNAzol protocol. The amounts of the recovered nucleic acid were quantitated by qPCR assay. 
A

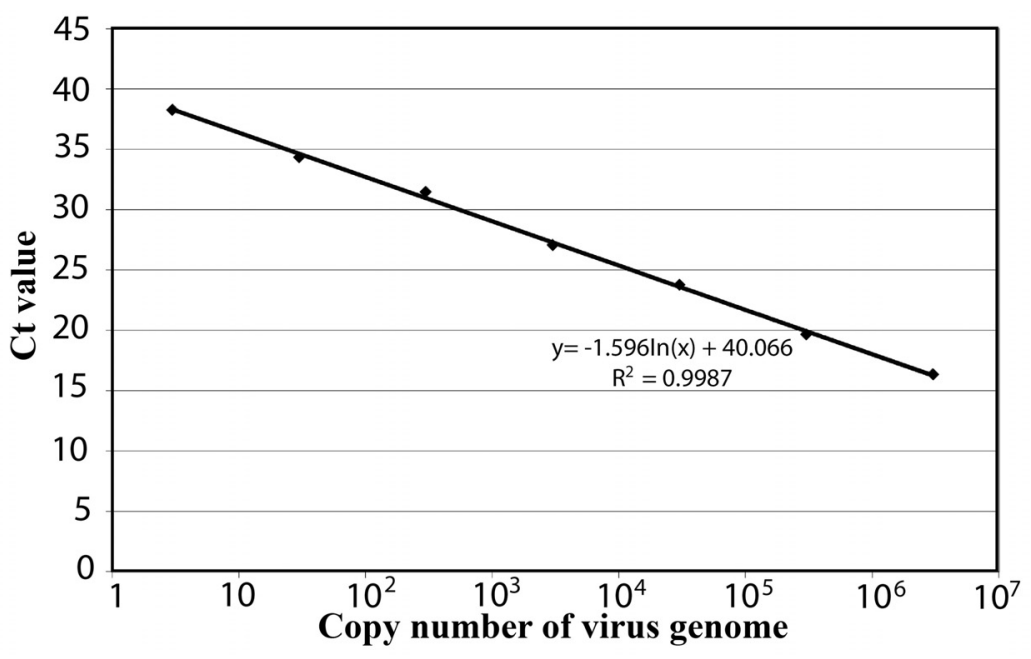

B

C
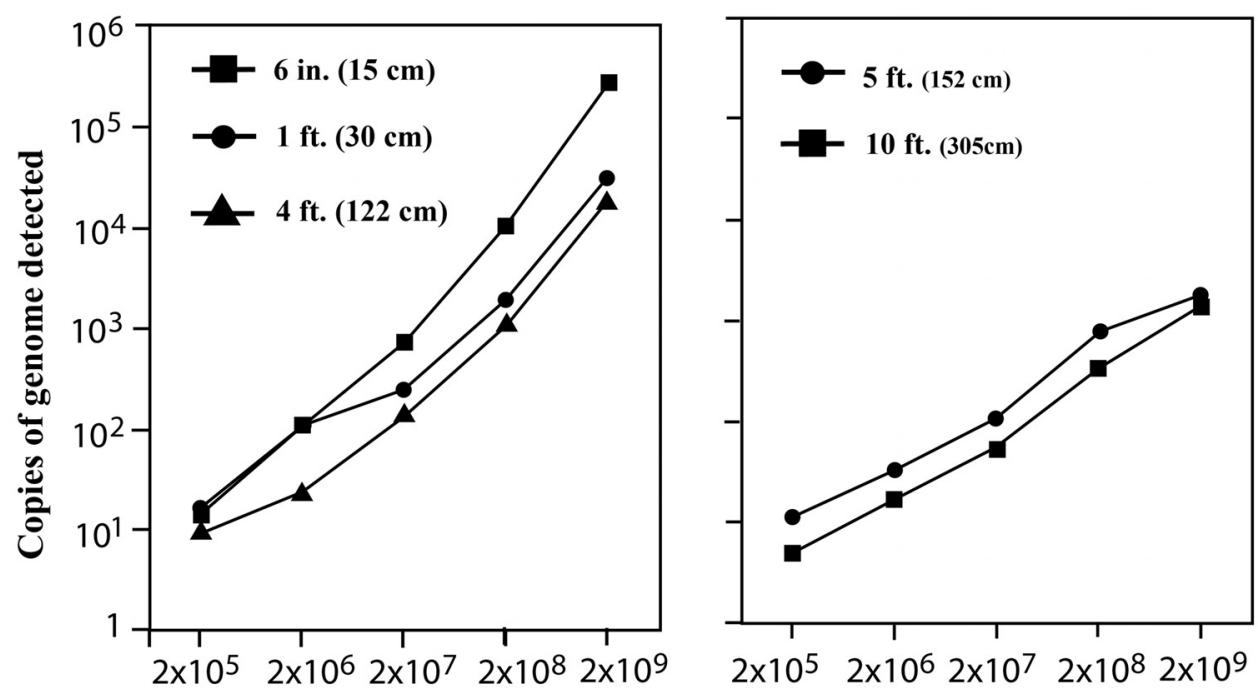

Amount of virus (genome copies equivalent) aerosolized

FIGURE 2 | (A) Standard curve for absolute quantification of BAd- $\triangle E 1 E 3$ genome. Tenfold serial dilutions of BAd $\Delta \mathrm{E} 1 \mathrm{E} 3$ genomes were subjected to Taqman qPCR, and the Ct values were plotted against the absolute numbers of viral genome. $(\mathbf{B}, \mathbf{C})$ Detection efficiency of aerosolized $B A d-\Delta E 1 E 3$ virus by ASAP System at different distances. Different concentrations of BAd- $\Delta E 1 E 3$ virus were aerosolized at different distances from the air inlet of the ASAP System, placed in $\mathbf{( B )}$ biosafety cabinet [72 inches $(183 \mathrm{~cm}) \times 24$ inches $(61 \mathrm{~cm}) \times 28$ inches $(71 \mathrm{~cm})]$, or $(\mathbf{C})$ in a room [9 feet $(274 \mathrm{~cm}) \times 10$ feet $(305 \mathrm{~cm}) \times 10.8$ feet $(329 \mathrm{~cm})]$. The amount of BAd- $\Delta$ E1E3 virus trapped on the PUFs was quantified by $\mathrm{qPCR}$ and depicted as geometric means.
The ASAP biosampler efficiently collected and trapped viral aerosols from the air. The minimum of $2 \times 10^{5}$ genome copies

TABLE 1 | Efficiency of recovery of BAd- $\triangle E 1 E 3$ virus from PUF.

\begin{tabular}{llll}
\hline $\begin{array}{l}\text { Virus amount } \\
\text { (p.f.u./50 } \boldsymbol{\mu l )}\end{array}$ & \multicolumn{2}{c}{$\begin{array}{c}\text { Copy number of virus genome } \\
\text { recovered }\end{array}$} & Percent recovery \\
\cline { 2 - 3 } & Pure virus & Spiked & \\
\hline $5.0 \mathrm{E}+01$ & $3.01 \mathrm{E}+01$ & $2.58 \mathrm{E}+01$ & 85.54 \\
$5.0 \mathrm{E}+03$ & $1.09 \mathrm{E}+02$ & $1.09 \mathrm{E}+02$ & 99.81 \\
$5.0 \mathrm{E}+05$ & $3.93 \mathrm{E}+04$ & $2.95 \mathrm{E}+04$ & 75.21 \\
$5.0 \mathrm{E}+07$ & $6.50 \mathrm{E}+06$ & $5.94 \mathrm{E}+06$ & 91.28
\end{tabular}

equivalent $\left(5 \times 10^{3}\right.$ p.f.u. $)$ of the input virus was detected (Figure 2B). The amount of viral genome detected decreased proportionately with the distance from the ASAP air inlet. However, even at increased distance, the ASAP system was sensitive enough to detect as low as $2 \times 10^{5}$ genome copies equivalent $\left(5 \times 10^{3}\right.$ p.f.u. $)$ of virus input. There was no crosscontamination from one PUF to another; the negative PUF in a cartridge remained negative after each run.

Subsequently, to mimic conditions similar to a normal work environment, the experiment was conducted in a room with a normal ventilation system. The ASAP system was placed in the room, and increasing amounts of BAd$\triangle \mathrm{E} 1 \mathrm{E} 3$ were aerosolized with the help of a nebulizer kept at 
distances of 5 feet $(152 \mathrm{~cm})$ and 10 feet $(305 \mathrm{~cm})$ from the machine. Similar to the experiment in the biosafety cabinet, the ASAP sampler efficiently collected and trapped the viral aerosols from the air. In each experiment, there was a dosedependent increase and a distance-dependent decrease in the number of genomes detected (Figure 2C). The minimum detection limit remained unchanged at $2 \times 10^{5}$ genome copies equivalent $\left(5 \times 10^{3}\right.$ p.f.u.) These results show that the ASAP bioaerosol sampler can efficiently monitor ambient air for viral pathogens.

\section{Discussion}

Over the last several decades, continuous air sampling coupled with rapid and accurate detection of potential pathogens in bioaerosols has attracted much attention. The ASAP bioaerosol sampler has been tested to sample bacteria and spores (Goransson et al., 2012) or metalliferous airborne particles (Moreno et al., 2015) under field conditions. However, the ASAP sampler had not yet been tested for collection of viral aerosols. In this study we investigated the efficacy of the ASAP bioaerosol sampler to collect and trap surrogate virus aerosols from the air and detect them using suitable assays. We demonstrated that in controlled laboratory conditions, the ASAP sampler can efficiently trap surrogate BAd- $\triangle E 1 E 3$ viral aerosols that can be extracted from the PUFs and identified using qPCR.

The purpose of bioaerosol sampling is to detect a biological agent release so that the impact of a biological agent attack can be reduced by executing appropriate responses with minimal delay. However, the conventional time-consuming laboratory methods involving culturing of microorganisms can take days to identify the pathogen. Molecular biology techniques such as qPCR are rapid, specific and sensitive enough to identify the genus, species or strain of the pathogen. These molecular assays can also be multiplexed to monitor more than one bio-threat agent at a time. As qPCR assays are quantitative, they can provide additional valuable information regarding the concentration of pathogens in the ambient air. We successfully detected the bioaerosols containing as low as $2 \times 10^{5}$ genome copies equivalent $\left(5 \times 10^{3}\right.$ p.f.u. $)$ of BAd- $\triangle \mathrm{E} 1 \mathrm{E} 3$. The technology of airborne pathogen detection is still in the trial stage with no approved device in practical application yet. Unfortunately, there are no set standards for the sensitivity of airborne pathogen detection. However, the detection of surrogate virus, released from a distance of $10 \mathrm{ft}$ $(305 \mathrm{~cm})$, and at a concentration as low as $2 \times 10^{5}$ genome copies equivalent $\left(5 \times 10^{3}\right.$ p.f.u. $)$ in a room the size of 972 cubic $\mathrm{ft}$ ( 27.5 cubic meters) is quite sensitive by many standards.

The majority of the currently available air sampling platforms are based on either impaction onto agar, impingement into liquid, or dry impaction (Kesavan and Sagripanti, 2015), and each has its limitations. The direct collection of microbes on agar is limited since not all species can be cultured and others have distinct nutrient requirements.
The agar surface can also get saturated in areas with high concentrations of microbes, and it cannot be used for viruses.

For viruses and other viable microorganisms, the collection of aerosols in liquid media/buffer is a preferred method. However, the high rate of sample collection usually results in violent bubbling of the collection fluid resulting in considerable loss of collection fluid within short time (Agranovski et al., 2004). Therefore, samplers based on liquid impinging or bubbling usually operate at lower speeds. Some advancement has been made to address these problems.

In the dry method (this study), the high volume of air impacting on the PUF results in a strong desiccation effect during sampling which dramatically diminishes the viability of most microorganisms. The inefficiency of dry impaction to collect viable particles is often considered a limitation; however, this method allows high rates of sample collection (>200 l/min) enabling rapid analysis of a larger sample volume from the environment.

The advantage of molecular techniques is that the genetic material can be detected even from inactive microorganisms. The specific detection of the genome of potentially dangerous microorganisms in the aerosol samples is evidence of a direct threat serious enough to raise an alarm and initiate appropriate measures. In this study we use only a DNA virus to test the efficacy of ASAP sampler. The iBASS cartridge is removed after every $4-8 \mathrm{~h}$ of operation for analysis of the microorganisms collected on the PUF, and during this time the genetic material, even from the RNA viruses, is expected to remain stable inside the capsid/shell of the inactive virus. It has been shown that phage PR772 and possibly other viruses as well, lost their infectivity before the genome degradation (Turgeon et al., 2014). Additionally, it has been demonstrated that the overall recovery of airborne viruses should be estimated based on the detection of genetic material rather than on viral infectivity (Verreault et al., 2010; Turgeon et al., 2014). The use of molecular biological methods is more likely to avoid false negative results than infectivity assays for the detection of airborne viruses (Verreault et al., 2010).

Aerosols are impacted on PUF which is often considered superior to other substrates such as glass bead beds, cellulose filters and other solid substrates. In particular, the PUF has minimum particle bounce and re-entrainment losses and has high collection efficiency without the need for greasing or oiling the substrate (Crook et al., 1997; Kavouras and Koutrakis, 2001; Lee et al., 2005). Furthermore, there is no pressure drop increase with particle accumulation, and it is easy to recover the impacted particles from the PUF.

In contrast to the ASAP bioaerosol system described in this study, some samplers utilize a combination of immunoassay and PCR to increase reliability and minimize the possibility of false positives (Hindson et al., 2005). Furthermore, the number of agents that can be detected in a sample is limited by the number of primer/probe sets used for multiplexing. If the primer/probe for a specific pathogen is not included in the mix, it would not be detected. It is expected that in the future pathogen detection will be based primarily on next-generation sequencing (NGS; 
Frey et al., 2014; Lecuit and Eloit, 2014). A key advantage of NGS is that it allows identification of a range of organisms (bacteria, viruses, fungi). Subsequent adaptations to couple the ASAP bioaerosol sampler with NGS platforms can potentially further enhance its accuracy, sensitivity and spectrum of detection.

The ASAP sampler is highly portable $(32 \mathrm{~cm} / \mathrm{side} ; 13.6 \mathrm{~kg})$, quiet in operation and has low energy usage (battery operable). The ASAP system equipment is extremely user friendly and allows changing the default settings of the machine to add attachments such as a GPS, wireless and Ethernet communication, temperature, and wind sensor, video exposure monitoring with regular and infrared cameras to identify anyone with fever who may be a carrier of a pathogen, and realtime sensors for radioactivity. ASAP can be controlled using an external trigger. All of these aspects of the ASAP 2800 system would make it a dynamic and powerful tool in the detection of airborne pathogens. The operation of the sampler can be adjusted depending on the requirement of the facility, for example $-1 \mathrm{~h}$ for each PUF for a total $8 \mathrm{~h}$ run or half an hour per PUF for a $4 \mathrm{~h}$ run. Sample analysis can be done once every $4-8 \mathrm{~h}$ or more frequently depending on the need of the facility. Once released, the virus-loaded fine bioaerosol particles can remain suspended for hours (Yang et al., 2011) and available for detection by bioaerosol samplers. At the end of each run, the sealed iBASS cartridge can be aseptically removed and immediately analyzed for the presence of any alarming genetic material. The rotating iBASS cartridge can hold as many as eight different sampling PUFs along with a blank and negative control. The option of eight different samples allows the selection of specific times to acquire samples. Since there is no cross contamination between the PUFs in an iBASS cartridge, the sampling at different times can be useful to detect the time period when the airborne pathogen was brought into the area. Standard operating procedures for an ASAP system have already been developed by Lovelace Respiratory Research Institute.

\section{References}

Agranovski, I. E., Agranovski, I. E., Safatov, A. S., Borodulin, A. I., Pyankov, O. V., Petrishchenko, V. A., et al. (2004). Inactivation of viruses in bubbling processes utilized for personal bioaerosol monitoring. Appl. Environ. Microbiol. 70, 6963-6967. doi: 10.1128/AEM.70.12.6963-6967.2004

Be, N. A., Be, N. A., Thissen, J. B., Fofanov, V. Y., Allen, J. E., Rojas, M., et al. (2015). Metagenomic analysis of the airborne environment in urban spaces. Microb. Ecol. 69, 346-355. doi: 10.1007/s00248-014-0517-z

Christian, M. D., Poutanen, S. M., Loutfy, M. R., Muller, M. P., and Low, D. E. (2004). Severe acute respiratory syndrome. Clin. Infect. Dis. 38, 1420-1427. doi: $10.1086 / 420743$

Crook, B., Stagg, L. C. K., Stancliffe, J. D., Futter, S. J., Griffiths, W. D., and Stewart, I. W. (1997). Assessment of the suitability of different substrate materials for bioaerosol sampling. Ann. Occup. Hyg. 41, 647-652. doi: 10.1093/annhyg/41.inhaled_particles_VIII.647

Frey, K. G., Herrera-Galeano, J. E., Redden, C. L., Luu, T. V., Servetas, S. L., Mateczun, A. J., et al. (2014). Comparison of three next-generation sequencing platforms for metagenomic sequencing and identification of pathogens in blood. BMC Genomics 15:96. doi: 10.1186/1471-2164-15-96

Goransson, J., Ke, R., Nong, R. Y., Howell, W. M., Karman, A., Grawé, J., et al. (2012). Rapid identification of bio-molecules applied for detection of biosecurity agents using rolling circle amplification. PLOS ONE 7:e31068. doi: 10.1371/journal.pone.0031068
For maximum efficacy in larger environments such as airports or stadiums, the bioaerosol samplers can be installed at strategic locations and work in conjunction with additional security surveillance such as video, personnel, and canine units. The ASAP bioaerosol sampler can also be used for evaluation of microbial contamination in the working environments in agricultural (Popescu et al., 2014; Sondergaard et al., 2014) or industry (Skora et al., 2014) settings, investigation of microbial metagenomics at distinct environments (Be et al., 2015) or in hospitals to track, identify, and control nosocomial infections (Sudharsanam et al., 2012).

\section{Conclusion}

Overall, these results suggest that the ASAP bioaerosol sampler is a promising system for monitoring ambient air that has been proven to work with viral pathogens. Additional testing to evaluate its feasibility in real world conditions such as small airports, hospitals, and military installations is recommended for its further development and subsequent use for the detection of real pathogens. This study also presents an ideal surrogate virus that can potentially be used in additional studies investigating viral aerosol sampling and detection. BAd- $\triangle \mathrm{E} 1 \mathrm{E} 3$ is a DNA virus that is quite stable in the environment. BAdV3 does not cause any harm to humans and to ensure additional safety it has been genetically modified to make it replication defective.

\section{Acknowledgments}

This work was partially supported by a grant from the Indiana State Department of Health. We are thankful to Jane Kovach for her excellent secretarial assistance.

Graham, F. L., and Prevec, L. (1991). "Manipulation of adenovirus vectors," in Methods of Molecular Biology: Gene Transfer and Expression Protocols, ed. E. J. Murray (Totowa: Humana Press), 109-128. doi: 10.1385/0-89603178-0:109

Hagleitner, C., Hierlemann, A., Lange, D., Kummer, A., Kerness, N., Brand, O., et al. (2001). Smart single-chip gas sensor microsystem. Nature 414, 293-296. doi: $10.1038 / 35104535$

Hartl, G. (2013). Novel coronavirus: the challenge of communicating about a virus which one knows little about. East. Mediterr. Health J. 19(Suppl. 1), S26-S30.

Hindson, B. J., McBride, M. T., Makarewicz, A. J., Henderer, B. D., Setlur, U. S., Smith, S. M., et al. (2005). Autonomous detection of aerosolized biological agents by multiplexed immunoassay with polymerase chain reaction confirmation. Anal. Chem. 77, 284-289. doi: 10.1021/ac0489014

Ho, J. (2002). Future of biological aerosol detection. Anal. Chim. Acta 457, 125-148. doi: 10.1016/S0003-2670(01)01592-6

Kavouras, I. G., and Koutrakis, P. (2001). Use of polyurethane foam as the impaction substrate/collection medium in conventional inertial impactors. Aerosol. Sci. Tech. 34, 46-56. doi: 10.1080/02786820118288

Kesavan, J., and Sagripanti, J. L. (2015). Evaluation criteria for bioaerosol samplers. Environ. Sci. Process. Impacts. 17, 638-645. doi: 10.1039/c4em00510d

Khanna, M., Kumar, P., Choudhary, K., Kumar, B., and Vijayan, V. K. (2008). Emerging influenza virus: a global threat. J. Biosci. 33, 475-482. doi: 10.1007/s12038-008-0066-z 
Lecuit, M., and Eloit, M. (2014). The diagnosis of infectious diseases by whole genome next generation sequencing: a new era is opening. Front. Cell. Infect. Microbiol. 4:25. doi: 10.3389/fcimb.2014.00025

Lee, S. J., Demokritou, P., and Koutrakis, P. (2005). Performance evaluation of commonly used impaction substrates under various loading conditions. J. Aerosol. Sci. 36, 881-895. doi: 10.1016/j.jaerosci.2004.11.006

McBride, M. T., Masquelier, D., Hindson, B. J., Makarewicz, A. J., Brown, S., Burris, K., et al. (2003). Autonomous detection of aerosolized Bacillus anthracis and Yersinia pestis. Anal. Chem. 75, 5293-5299. doi: 10.1021/ac034722v

Menrath, A., Tomuzia, K., Frentzel, H., Braeunig, J., and Appel, B. (2014). Survey of systems for comparative ranking of agents that pose a bioterroristic threat. Zoonoses. Public Health 61, 157-66. doi: 10.1111/zph.12065

Moreno, T., Martins, V., Querola, X., Jonesc, T., BéruBéd, K., Minguillóna, M. C., et al. (2015). A new look at inhalable metalliferous airborne particles on rail subway platforms. Sci. Total Environ. 505, 367-375. doi: 10.1016/j.scitotenv.2014.10.013

Oppliger, A., Masclaux, F. G., and Niculita-Hirzel, H. (2011). Assessment of airborne microorganisms by real-time PCR: optimistic findings and research challenges. Front. Biosci. (Schol. Ed.) 3:445-453 doi: 10.2741/s163

Pan, Y. L., Aptowicz, K. B., Chang, R. K., Hart, M., and Eversole, J. D. (2003). Characterizing and monitoring respiratory aerosols by light scattering. Opt. Lett. 28, 589-591. doi: 10.1364/OL.28.000589

Pohanka, M., and Kuca, K. (2010). Biological warfare agents. EXS 100, 559-578. doi: 10.1007/978-3-7643-8338-1_17

Popescu, S., Borda, C., Diugan, E., and Oros, D. (2014). Microbial air contamination in indoor and outdoor environment of pig farms. Animal Sci. Biotech. 47, 182-187.

Pyankov, O. V., Agranovski, I. E., Pyankova, O., Mokhonova, E., Mokhonov, V., Safatov, A. S., et al. (2007). Using a bioaerosol personal sampler in combination with real-time PCR analysis for rapid detection of airborne viruses. Environ. Microbiol. 9, 992-1000. doi: 10.1111/j.1462-2920.2006. 01226.x

Rider, T. H., Petrovick, M. S., Nargi, F. E., Harper, J. D., Schwoebel, E. D., Mathews, R. H., et al. (2003). A B cell-based sensor for rapid identification of pathogens. Science 301, 213-215. doi: 10.1126/science. 1084920

Sengupta, A., Brar, N., and Davis, E. J. (2007). Bioaerosol detection and characterization by surface-enhanced Raman spectroscopy. J. Colloid Interface Sci. 309, 36-43. doi: 10.1016/j.jcis.2007.02.015

Sharma, A., Bangari, D. S., Tandon, M., Pandey, A., HogenEsch, H., and Mittal, S. K. (2009). Comparative analysis of vector biodistribution, persistence and gene expression following intravenous delivery of bovine, porcine and human adenoviral vectors in a mouse model. Virology 386, 44-54. doi: 10.1016/j.virol.2009.01.008

Skora, J., Gutarowska, B., Stepien, L., Otlewska, A., and Pielech-Przybylska, K. (2014). The evaluation of microbial contamination in the working environment of tanneries. Med. Pr. 65, 15-32. doi: 10.13075/mp.5893. 2014.005

Skottrup, P. D., Nicolaisen, M., and Justesen, A. F. (2008). Towards on-site pathogen detection using antibody-based sensors. Biosens. Bioelectron. 24, 339-348. doi: 10.1016/j.bios.2008.06.

Sondergaard, M. S., Josefsen, M. H., Löfström, C., Christensen, L. S., Wieczorek, K., Osek, J., et al. (2014). Low-cost monitoring of Campylobacter in poultry houses by air sampling and quantitative PCR. J. Food. Prot. 77, 325-330. doi: 10.4315/0362-028X

Sudharsanam, S., Swaminathan, S., Ramalingam, A., Thangavel, G., Annamalai, R., Steinberg, R., et al. (2012). Characterization of indoor bioaerosols from a hospital ward in a tropical setting. Afr. Health Sci. 12, 217-225. doi: 10.4314/ahs.v12i2.22

Turgeon, N., Toulouse, M. J., Martel, B., Moineau, S., and Duchaine, C. (2014). Comparison of five bacteriophages as models for viral aerosol studies. Appl. Environ. Microbiol. 80, 4242-4250. doi: 10.1128/AEM. 00767-14

Usachev, E. V., and Agranovski, I. E. (2012). Internally controlled PCR system for detection of airborne microorganisms. J. Environ. Monit. 14, 1631-1637. doi: 10.1039/c2em30019b

van Olphen, A. L., Tikoo, S. K., and Mittal, S. K. (2002). Characterization of bovine adenovirus type $3 \mathrm{E} 1$ proteins and isolation of E1-expressing cell lines. Virology 295, 108-118. doi: 10.1006/viro.2002.1389

Verreault, D., Rousseau, G., Gendron, L., Masse, D., Moineau, S., and Duchaine, C. (2010). Comparison of polycarbonate and polytetrafluoroethylene filters for sampling of airborne bacteriophages. Aerosol. Sci. Tech. 44, 197-201. doi: $10.1080 / 02786820903518899$

Yang, W., Elankumaran, S., and Marr, L. C. (2011). Concentrations and size distributions of airborne influenza A viruses measured indoors at a health centre, a day-care centre and on aeroplanes. J. R. Soc. Interface 8, 1176-1184. doi: 10.1098/rsif.2010.0686

Zink, T. K. (2011). Anthrax attacks: lessons learned on the 10th anniversary of the anthrax attacks. Disaster. Med. Public Health Prep. 5, 173-174. doi: $10.1001 / \mathrm{dmp} .2011 .71$

Conflict of Interest Statement: The authors declare that the research was conducted in the absence of any commercial or financial relationships that could be construed as a potential conflict of interest.

Copyright (c) 2015 Sharma, Clark, McGlothlin and Mittal. This is an open-access article distributed under the terms of the Creative Commons Attribution License (CC BY). The use, distribution or reproduction in other forums is permitted, provided the original author(s) or licensor are credited and that the original publication in this journal is cited, in accordance with accepted academic practice. No use, distribution or reproduction is permitted which does not comply with these terms. 